\title{
UMA ANÁLISE DO TRABALHO E DO TRABALHADOR CONTEMPORÂNEO POR MEIO DO PSICODRAMA
}

\section{A psychodrama's analyses of the contemporaneous work and workers conditions}

Antonio Vitorino Cardoso Neto ${ }^{1}$

Sílvio Paulo Botomé

Almeida, L (2004). 0 trabalhador no mundo contemporâneo: psicodrama nas organizações. São Paulo: Agora.

Pode estar enganado quem considera o Psicodrama como sendo apenas uma técnica de trabalho. Talvez seja necessário descobrir uma outra face do psicodrama. Normalmente associadas à atividade clínica, as técnicas de dramatização e o role-playing são os usos mais conhecidos do Psicodrama. Há, porém, outras possibilidades de uso desse procedimento de trabalho que talvez sejam ainda grandemente desconhecidas. O que dizer, por exemplo, do Psicodrama aplicado a situações típicas de processos organizacionais, sejam eles administrativos, operacionais, sociais ou técnicos? E o que dizer de um exame de aplicação do Psicodrama realizado de forma detalhada e com instrumentos científicos em um contexto organizacional? E, para quem quiser ou precisar, isso é encontrado no livro de Lúcia Almeida, "O trabalhador no mundo contemporâneo: Psicodrama nas organizações" (São Paulo: Editora Ágora, 2004). Ela revê conceitos fundamentais propostos por Jacó Levy Moreno, criador do Psicodrama. Examina conceitos sobre trabalho e as organizações na perspectiva de Caltells, Chesnaux e Antunes, ampliando-os para o que denominou de "mundo do trabalho". O livro é inovador, revelador e rico em novas informações sobre possibilidades de uso do Psicodrama em organizações. Para todos que trabalham com treinamento, no Brasil em particular, vale a pena conhecer um texto sobre a utilização de técnicas de Psicodrama em organizações, principalmente quando o cenário é o contexto do trabalho e tem como protagonista 0 trabalhador que vive no país neste início do século XXI.

1 Universidade Federal de Santa Catarina, Mestrando em Psicologia, Psicólogo Especialista em Administração de Recursos Humanos pela Universidade Federal do Paraná.

Endereço: Rua Prof. Sebastião Paraná, 460/47 - CEP 80320-070 - Curitiba Paraná e-mail: vitorinocardoso@yahoo.com.br

2 Universidade Federal de Santa Catarina, Professor do Programa de Pós-graduação em Psicologia, Doutor em Psicologia pela Universidade de São Paulo. 
Ao apresentar o exame do Psicodrama, por meio de sua aplicação em organizações, a autora produz um texto em linguagem acessível tanto para aqueles que trabalham com organizações (e com situações de aprendizagem ou de treinamento) quanto para aqueles que não dominam os conceitos básicos do Psicodrama. O modo como a autora desenvolve os capítulos iniciais traz uma contextualização desses conceitos, que servem como uma introdução útil e esclarecedora para o leitor iniciante. Ao mesmo tempo, são úteis como uma revisão deles, o que pode servir também para profissionais mais experientes.

O protagonista do livro é o trabalhador em estado de sofrimento psicológico diante de um contexto organizacional influenciado pelas mudanças rápidas no processo de trabalho. Novas tecnologias de informação, globalização de mercados e as modificações nos critérios e condições de emprego, entre outras alterações, têm exigido mudanças no comportamento dos trabalhadores. Trabalhar em equipe, apresentar criatividade, iniciativa, autonomia e responsabilidade são alguns dos "predicados" exigidos do trabalhador para adequar-se ao "mundo" do trabalho no início do século XXI. Diante dessas exigências, o trabalhador sofre por não ter esses "predicados" ou recursos disponíveis, transformando essa situação em uma ameaça para a possibilidade de obter emprego ou de nele permanecer, na sociedade em que vive.

Nessas condições do "mundo do trabalho", a autora destaca que é preciso auxiliar o trabalhador a minimizar seu sofinmento por meio da reflexão sobre seu papel profissional. Refletir é um termo amplo que, utilizado pela autora no decorrer do texto, assume vários sentidos: tomar conhecimento das necessidades profissionais, identificar caractenísticas pessoais desenvolvidas e a serem desenvolvidas, ser responsável pelo trabalho e emprego, apresentar ações e atitudes de autonomia, entre outros. Todos esses sentidos indicam tipos de comportamentos que 0 trabalhador necessita aprender (ou desenvolver) para aperfeiçoar seu desempenho em suas funções e com isso manter-se integrado ao trabalho, apesar das mudanças que ocorrem. Ajudaria muito ao leitor se todos esses sentidos, principalmente o comportamental, fossem mais detalhados e aprofundados pela autora. No entanto, vale a indicação de que, no texto, a expressão refletir é muito mais do que uma análise a posteriori de algo. 0 termo refere-se a vários tipos de comportamentos que podem ser identificados, aprendidos e desenvolvidos por meio da uti- lização do Psicodrama nas organizações.

Por que o Psicodrama para fazer isso?A autora demonstra que ele é um método adequado e eficaz, pois articula a realidade concreta com os conhecimentos sobre os processos que a constituem, fazendo o protagonista trabalhador "sintetizar" conhecimento e conduta perante a "realidade" (relacionar-se de uma nova maneira com os processos e fenômenos com os quais se defronta nessa "realidade", coerentemente com o conhecimento disponível). Para demonstrar essa eficácia, a autora realiza uma pesquisa com um grupo de funcionánios de uma empresa que passa por processos de mudanças que estão ocorrendo em larga escala no início do século XXI. Para esses trabalhadores, é necessário que apresentem comportamentos proativos, de iniciativa, de criatividade e que constituem uma efetiva capacidade de trabalhar em equipes. No desenvolvimento dessas características, o Psicodrama pode contribuir de modo até privilegiado, pois seus constructos (conceituais ou teónicos) estão baseados nos estudos da espontaneidade-criatividade, dos aspectos relacionais e desempenho de papéis, entre outros. Tais conceitos, articulados com realidade vivida pelo grupo, podem auxiliar na compreensão da relação do trabalhador com sua organização ou com seu contexto de trabalho.

O livro provoca a curiosidade para saber de que forma, em que condições, com que sujeitos foi utilizado e quais resultados o Psicodrama obteve ao ser aplicado em uma organização e, ao descobrir isso, o leitor pode identificar outras possibilidades de aplicação do Psicodrama. Tudo isso faz com que sua leitura seja indispensável não só para psicólogos e psicodramatistas, mas também para todos os profissionais da área de treinamento. Pode servir, inclusive, como um modelo de estudo a ser desenvolvido por profissionais da área para divulgar seus conhecimentos, tarefa iniciada por Moreno nos Estados Unidos no século passado e, agora, promovida por Lúcia Almeida no Brasil, com o seu trabalho sobre "O trabalhador no mundo contemporâneo: Psicodrama nas Organizações". Vale a pena conferir como a autora mostra que o Psicodrama pode ser mais do que uma técnica de "trabalho" de profissionais da Psicologia Organizacional, Pedagogia e Administração de Empresa.
Recebido em/Received in: 06/03/2006 Aprovado em/Approved in: 10/04/2006 